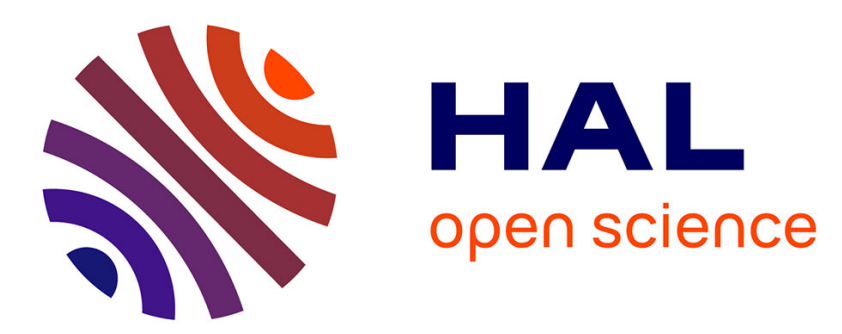

\title{
Explicit formulations of adhesive wear extension in fretting interfaces applying the contact oxygenation concept
}

\author{
Soha Baydoun, Pierre Arnaud, Siegfried Fouvry
}

\section{To cite this version:}

Soha Baydoun, Pierre Arnaud, Siegfried Fouvry. Explicit formulations of adhesive wear extension in fretting interfaces applying the contact oxygenation concept. Wear, 2022, 488-489, pp.204147. 10.1016/j.wear.2021.204147 . hal-03453452

HAL Id: hal-03453452

https://hal.science/hal-03453452

Submitted on 29 Nov 2021

HAL is a multi-disciplinary open access archive for the deposit and dissemination of scientific research documents, whether they are published or not. The documents may come from teaching and research institutions in France or abroad, or from public or private research centers.
L'archive ouverte pluridisciplinaire HAL, est destinée au dépôt et à la diffusion de documents scientifiques de niveau recherche, publiés ou non, émanant des établissements d'enseignement et de recherche français ou étrangers, des laboratoires publics ou privés. 


\title{
Explicit formulations of adhesive wear extension in fretting interfaces applying the contact oxygenation concept
}

\author{
Soha Baydoun ${ }^{a_{*}}$, Pierre Arnaud ${ }^{b_{*}}$, Siegfried Fouvry ${ }^{a_{*}}$ \\ ${ }^{a}$ Ecole Centrale de Lyon, LTDS Laboratory, 36 av Guy de Collongue, 69130 Ecully, France \\ ${ }^{b}$ MINES ParisTech, Centre des Matériaux, 63-65 rue Henri-Auguste Desbrueres, F-91003 Évry cedex, \\ France \\ *Corresponding authors email addresses: soha.baydoun@ec-lyon.fr (S. Baydoun), pierre.arnaud@mines- \\ paristech.fr (P. Arnaud) and siegfried.fouvry@ec-lyon.fr (S. Fouvry)
}

\section{Abstract}

Adhesive wear extension in metal fretting contacts was previously related to the partial pressure of oxygen gas in a porous third body layer. Below a threshold value, the surface oxidation is no more possible and adhesive wear prevails in the inner part of the interface. The contact oxygenation concept (COC) allowing the prediction of the dioxygen partial pressure profile was recently simulated for a 2D surface analysis (i.e. 3D contact) using a numerical Advection-Dispersion-Reaction (ADR) approach. In this study, a simple explicit formulation is derived to capture COC response using a 1D surface analysis (i.e. 2D contact hypothesis).

Keywords: Abrasive-adhesive fretting wear; Long-flat contacts; Contact oxygenation concept (COC); Advection-Dispersion-Reaction model (ADR).

\section{Introduction}

Fretting takes place in contact surfaces undergoing micro-displacement oscillatory movements where most of the interface is hidden from the outer environment $[1,2]$. When relatively large displacement amplitudes are applied, gross slip fretting takes place inducing wear through the formation and expulsion of debris particles. 
Several wear mechanisms can be activated during fretting including fatigue, abrasion, adhesion, corrosion, etc. [3]. Adhesion is one of the most drastic aspects of wear as it causes local overstresses triggering nucleation and propagation of incipient fretting cracks in addition to micro-welding process [4].

The extension of adhesive wear in a fretting interface can be illustrated considering the contact oxygenation concept (COC) [5-10]. This latter describes the interfacial oxygen flow such that adhesion prevails in the middle of the interface whenever the oxygen partial pressure $\left(\mathrm{P}_{\mathrm{O}_{2}}\right)$ falls below a threshold value $\left(\mathrm{P}_{\mathrm{O}_{2}, \text { th }}\right)$, otherwise, in the lateral sides, abrasive-oxidational wear is observed (Fig.1). This lateral abrasion zone can be assessed using the "oxygen distance $\mathrm{d}_{0}$ " parameter [11] which is the distance from the contact edges to the boundaries of adhesion domain (Fig. 1).

Oxygen transport within the interface was recently simulated using an advectiondispersion-reaction approach (ADR) [12] such that the debris bed is considered a porous medium crossed by atmospheric gases namely oxygen and nitrogen. These gases interact with the freshly exposed metal through the friction power dissipated at the interface (Fig. 1) which is formalized through the Archard power density factor $\omega^{*}=$ p.v (with $p$ being the contact pressure and $v$ being the sliding speed). For such 2D surface analysis (i.e. 3D contact), complex finite difference procedures are required. However, assuming the same hypothesis, it was shown in [13] that this complete model can be reduced to an explicit analytical solution based on Bessel functions for axisymmetric circular interfaces. In this work, it can be shown that ADR model can be further reduced to a simple exponential function for $1 \mathrm{D}$ linear contact equivalent for instance to a long 
flat contact configuration. This simple closed form of $C O C$ is compared with complete 2D simulations and discussed regarding dedicated experiments.
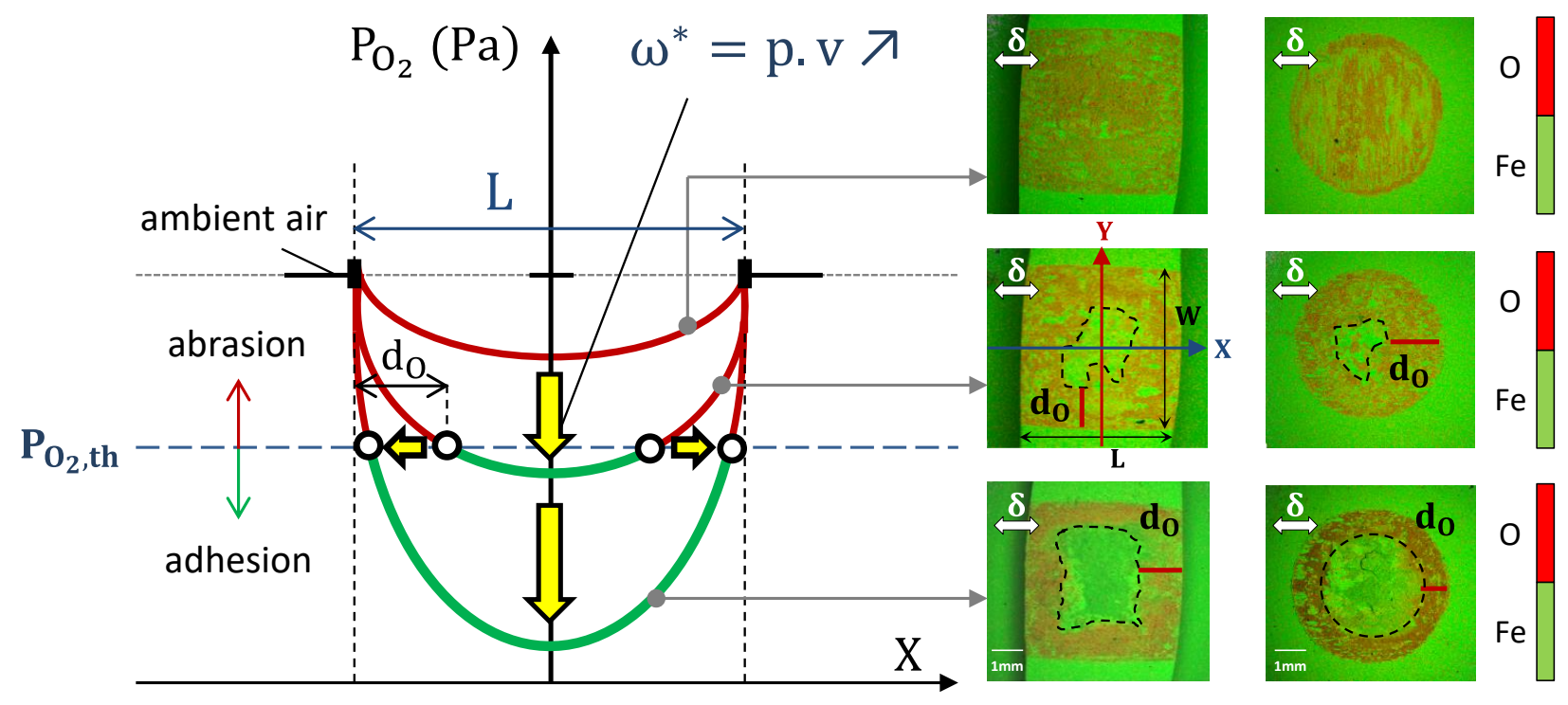

Fig.1. Illustration of the contact oxygenation concept (COC) showing the transition from pure abrasive to a mixed abrasive-adhesive wear and application of the latter on flat circular [13] and square [12] shaped fretting interfaces as reflected by the EDX maps.

\section{Description of the ADR approach}

ADR approach, being thoroughly illustrated in $[12,13]$, is concisely recapped in this section. This model consists in obtaining the oxygen partial pressure profile within the interface by establishing a balance between the advective and dispersive transport of $\mathrm{O}_{2}$ from the ambient air within the porous debris layer and the reaction process (i.e. the consumption rate of the available $\mathrm{O}_{2}$ molecules with the freshly exposed metal surface by friction). The ADR continuity equation of a gas component " $\mathrm{i}$ " $\left(\mathrm{i}=\mathrm{O}_{2}\right.$ or $\left.\mathrm{N}_{2}\right)$ is shown in Eq. 1. 
$a \frac{d P_{i}}{d t}=-\nabla \cdot\left(J_{i}\right)+R_{i}=-\nabla \cdot\left(J_{a, i}+J_{d, i}\right)+R_{i}=-\nabla \cdot\left(-D_{i} \nabla P_{i}+v P_{i}\right)+R_{i}$

Where $P_{i}$ is the gas partial pressure, $J_{i}$ the general molar flux, $J_{a, i}$ the advective flux, $J_{d, i}$ the dispersive flux, $R_{i}$ the reaction rate, a the debris bed porosity, $D_{i}$ the dispersion coefficient, and $\mathrm{v}$ the gas-mixture advection velocity in the porous debris bed. These latter parameters are computed applying the models and equations which are completely detailed in Ref. [12].

The current study neglects the metal reaction with nitrogen gas (i.e. $\mathrm{R}_{\mathrm{N}_{2}} \approx 0$ ) despite the observation of nitriding process in some fretting contacts as titanium alloys [6,14]. In contrary, oxygen gas interacts with the metal surface such that the reaction rate $\left(\mathrm{R}_{\mathrm{O}_{2}}\right)$ is represented as a first-order decay rate of $\mathrm{O}_{2}$ (Eq. 2) which is consumed due to the oxidation of the metal surface exposed by friction process represented by the oxidation rate coefficient $\mathrm{r}_{\mathrm{O}_{2}}$.

$\mathrm{R}_{\mathrm{O}_{2}}=-\mathrm{r}_{\mathrm{O}_{2}} \times \mathrm{P}_{\mathrm{O}_{2}}$

$\mathrm{r}_{\mathrm{O}_{2}}$ is estimated using a simple empirical phenomenological expression considering the Archard power density factor $\omega^{*}$ which is equal to the "p.v" factor.

$\mathrm{r}_{\mathrm{O}_{2}}=\beta\left(\frac{\omega^{*}}{\omega_{\mathrm{ref}}^{*}}\right)^{\gamma}$ with $\omega^{*}=\mathrm{p} \times \mathrm{v}=4 . \mathrm{p} \cdot \delta_{\mathrm{g}} \cdot \mathrm{f}$

This model was applied to investigate the adhesive wear extension for a low-alloyed (34NiCrMo16) flat-on-flat interface [12]. One interest of this flat-on-flat contact configuration is the possibility to maintain a constant contact area and contact pressure 
during wear process. The reaction rate parameters (Eq. 3) were calibrated in [12] leading to $\beta=394.63$ and $\gamma=0.47$ [12]. $\omega_{\text {ref }}^{*}$ is the Archard power density factor at the reference conditions defined in [12] having a sliding amplitude $\delta_{g}= \pm 100 \mu \mathrm{m}$, mean contact pressure $p=100 \mathrm{MPa}$, and a sliding frequency $\mathrm{f}=1 \mathrm{~Hz}$ (with a square contact area $A=5 \times 5=25 \mathrm{~mm}^{2}$ and a test duration $=20000$ fretting cycles) such that $\omega_{\text {ref }}=0.04 \mathrm{~W} / \mathrm{mm}^{2}$. Very nice predictions of the partition between adhesive and abrasive wear domains were achieved taking into account the effect of frequency, contact pressure and contact size. However, 2D surface analysis requires complete numerical simulations which do not permit an explicit correlation between the loading and debris bed parameters and the evolution of $\mathrm{O}_{2}$ partial pressure profile. Recently [13], assuming a steady state condition of the ADR where the effect of both the nitrogen gas and the advection process are neglected, it was shown that for a flat asymmetrical circular interface of an external radius $\mathrm{R}, \mathrm{ADR}$ equation can be solved analytically such that the di-oxygen partial pressure versus the radial distance " $r$ " $\left(\mathrm{R}_{0}<\mathrm{r}<\mathrm{R}\right)$ can be evaluated using the following simple analytical expression:

$$
\begin{aligned}
& \mathrm{P}_{\mathrm{O}_{2}}(\mathrm{r})=\mathrm{A} \times \mathrm{I}_{0}(\eta \mathrm{r})+\mathrm{B} \times \mathrm{K}_{0}(\eta \mathrm{r}) \\
& \mathrm{I}_{0}(\eta \mathrm{r})=\sum_{\mathrm{n}=0}^{\infty} \frac{1}{(\mathrm{n} !)^{2}}\left(\frac{1}{2} \eta r\right)^{2 \mathrm{n}} \\
& \mathrm{K}_{0}(\eta \mathrm{r})=\int_{0}^{\infty} \cos (\eta \mathrm{r} \sinh (\mathrm{t})) \mathrm{dt}=\int_{0}^{\infty} \frac{1}{\sqrt{\mathrm{t}^{2}+1}} \cos (\eta \mathrm{rt}) \mathrm{dt} \\
& \mathrm{A}=\frac{\mathrm{K}_{1}\left(\eta \mathrm{R}_{0}\right) \times \mathrm{P}_{\mathrm{O}_{2}}(\mathrm{R})}{\mathrm{I}_{1}\left(\eta \mathrm{R}_{0}\right) \mathrm{K}_{0}(\eta \mathrm{R})+\mathrm{I}_{0}(\eta \mathrm{R}) \mathrm{K}_{1}\left(\eta \mathrm{R}_{0}\right)} \\
& \mathrm{B}=\frac{\mathrm{I}_{1}\left(\eta \mathrm{R}_{0}\right) \times \mathrm{P}_{\mathrm{O}_{2}}(\mathrm{R})}{\mathrm{I}_{1}\left(\eta \mathrm{R}_{0}\right) \mathrm{K}_{0}(\eta \mathrm{R})+\mathrm{I}_{0}(\eta \mathrm{R}) \mathrm{K}_{1}\left(\eta \mathrm{R}_{0}\right)}
\end{aligned}
$$


where $\eta=\sqrt{\frac{r_{\mathrm{O}_{2}}}{D_{\text {diffusion, } O_{2}}}}$

Due to the singularity existing at $r=R_{0} \rightarrow 0$ as detailed in [15], the solution can be further simplified to:

$\mathrm{P}_{\mathrm{O}_{2}}(\mathrm{r})=\frac{\mathrm{I}_{0}(\eta \mathrm{r})}{\mathrm{I}_{0}(\eta \mathrm{R})} \times \mathrm{P}_{\mathrm{O}_{2}}(\mathrm{R})$

$\mathrm{I}_{0}(\eta \mathrm{r})=\sum_{\mathrm{n}=0}^{\infty} \frac{1}{(\mathrm{n} !)^{2}}\left(\frac{1}{2} \eta \mathrm{r}\right)^{2 \mathrm{n}}$ and $\eta=\sqrt{\frac{\mathrm{r}_{\mathrm{O}_{2}}}{\mathrm{D}_{\text {diffusion, } \mathrm{O}_{2}}}}$

This analytical solution depends mainly on the reaction rate coefficient " $\mathrm{r}_{2}$ " and the

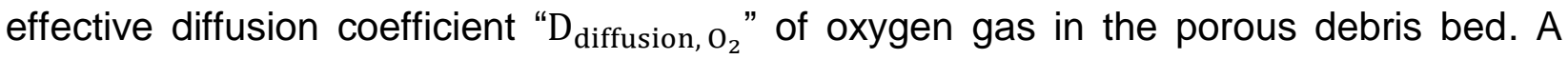
parametric analysis comparing the analytical solution versus the complete numerical simulations confirm the stability of the proposal. Deepening this approach, it will be demonstrated that a simpler expression of $\mathrm{O}_{2}$ partial pressure can be derived for $1 \mathrm{D}$ surface configuration (i.e. 2D flat contact). This 1D surface will be approximated experimentally to a flat geometry having a long "Y" transverse width (W) compared to a collinear "X" contact length (L). A similar 34NiCrMo16 interface will be considered so that the same calibration parameters can be applied to simulate the experiments (i.e. $\beta=394.63$ and $\gamma=0.47$ ) as detailed in [12]. Additionally, the threshold oxygen partial pressure " $\mathrm{P}_{2}$,th" and the debris bed porosity will be assumed equal to $0.1 \mathrm{~Pa}$ and 0.48 respectively for the same assumptions discussed in [12]. 


\section{One dimensional analytical solution of the ADR approach}

Cartesian ADR continuity equation was solved numerically in [12] leading to a good description of the adhesive wear extension. However, in order to explicitly understand the role of the debris bed parameters and the oxidation reaction coefficient on the partition of abrasive and adhesive wear, numerical solution is not sufficient and an analytical solution is requested. Nonetheless, deriving the analytical solution is not straightforward and requires many simplifications of the highly-coupled parameters in the ADR equation. Thus, the following assumptions are suggested:

-The analytical solution will be estimated at steady state, hence:

$\frac{\mathrm{dP}_{\mathrm{O}_{2}}}{\mathrm{dt}}=0 \Rightarrow-\nabla \cdot\left(-\mathrm{D}_{\mathrm{O}_{2}} \nabla \mathrm{P}_{\mathrm{O}_{2}}+\mathrm{vP}_{\mathrm{O}_{2}}\right)+\mathrm{R}_{\mathrm{O}_{2}}=0$

-One dimensional contact is assumed such that the dispersion, advection and reaction coefficients are supposed to be constant (i.e. $\mathrm{D}_{\mathrm{O}_{2}}=$ constant, v=constant, $\mathrm{r}_{\mathrm{O}_{2}}=$ constant):

$\mathrm{D}_{\mathrm{O}_{2}} \nabla^{2} \mathrm{P}_{\mathrm{O}_{2}}-v \nabla \mathrm{P}_{\mathrm{O}_{2}}-\mathrm{r}_{\mathrm{O}_{2}} \mathrm{P}_{\mathrm{O}_{2}}=0 \Rightarrow \mathrm{D}_{\mathrm{O}_{2}} \frac{\mathrm{d}^{2} \mathrm{P}_{\mathrm{O}_{2}}}{d x^{2}}-\mathrm{v} \frac{d \mathrm{P}_{\mathrm{O}_{2}}}{\mathrm{dx}}-\mathrm{r}_{\mathrm{O}_{2}} \mathrm{P}_{\mathrm{O}_{2}}=0$

Eq. 12 is a second order ordinary differential equation whose solution is as follows (A \& B are constants):

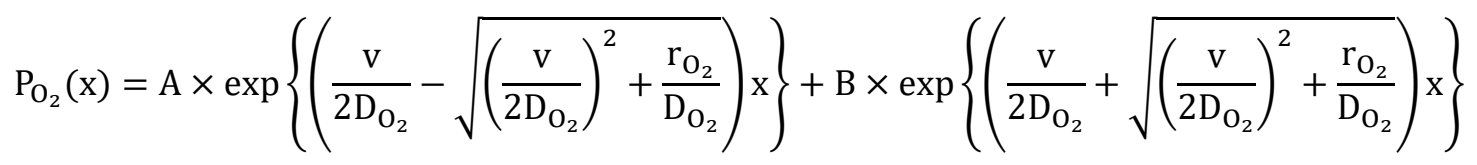

In order to further simplify the above analytical solution and reduce the number of parameters in the model, the relative importance of advection to diffusion is estimated. This can be done using Peclet number "Pe" which is the ratio of the time necessary for 
the gas molecules to traverse a characteristic length $\mathrm{L}$ by advection and the time required to travel the same length by diffusion (Eq. 14) [16]. The characteristic length $\mathrm{L}$ represents the distance the gas molecules can travel which is equal to the contact size and $\mathrm{D}_{\text {diffusion, } \mathrm{O}_{2}}$ is the effective diffusion coefficient of $\mathrm{O}_{2}$. Based on this, oxygen gas flow will be diffusion-controlled if $\mathrm{Pe}<1$ [16].

$\mathrm{Pe}=\frac{|\mathrm{v}| \mathrm{L}}{\mathrm{D}_{\text {diffusion, } \mathrm{O}_{2}}}$

Former study [13] linked to this work involving fretting tests of $34 \mathrm{NiCrMo16}$ circular flaton-flat contact revealed that the average Peclet number "Pe" does not exceed one for a wide range of fretting loadings investigated within the same study. Besides, varying the advection speed by several orders of magnitude by changing the debris bed intrinsic permeability and particle size had no significant effect on the oxygen distance parameter and adhesive wear extension as shown in [12]. Hence, keeping the same parameters in this study, it can be suggested that the relative importance of oxygen gas advection to diffusion is weak implying a negligible advection speed $(\mathrm{v} \approx 0)$. Doing so, the analytical solution can be simplified to this very simple exponential function expressing the $\mathrm{O}_{2}$ partial pressure profile as a function of the axial position " $\mathrm{x}$ ":

$\mathrm{P}_{\mathrm{O}_{2}}(\mathrm{x})=\mathrm{A} \times \exp \left(-\sqrt{\frac{\mathrm{r}_{\mathrm{O}_{2}}}{\mathrm{D}_{\mathrm{O}_{2}}} \mathrm{x}}\right)+\mathrm{B} \times \exp \left(\sqrt{\frac{\mathrm{r}_{\mathrm{O}_{2}}}{\mathrm{D}_{\mathrm{O}_{2}}} \mathrm{x}}\right)$

In the absence of advection, the dispersion coefficient $\mathrm{D}_{\mathrm{O}_{2}}$ will be equal to the effective molecular diffusion $\mathrm{D}_{\text {diffusion, } \mathrm{O}_{2}}$ of the gas component which is the random spreading of the gas molecules due to concentration gradients. $D_{\text {diffusion, } \mathrm{O}_{2}}$ is equal to the product of the oxygen gas diffusion coefficient " $\mathrm{D}_{\mathrm{O}_{2}, \mathrm{~m}}$ " in a homogeneous mixture of gases and the 
tortuosity " $\tau$ " which depicts the diminution of the effective diffusion coefficient caused by the solid-phase that reduces the cross-sectional area available for diffusion. These parameters are estimated previously in $[12,13]$. The tortuosity " $\tau$ " is expressed empirically as a function of the debris bed porosity "a" considering Moldrup et al. model [17] (Eq. 16).

$\mathrm{D}_{\mathrm{O}_{2}}=\mathrm{D}_{\text {diffusion, } \mathrm{O}_{2}}=\tau \mathrm{D}_{\mathrm{O}_{2}, \mathrm{~m}}=0.66 \times \mathrm{a} \times \mathrm{D}_{\mathrm{O}_{2}, \mathrm{~m}}$

The constants "A" and "B" (Eq. 17 \& 18) are estimated assuming the oxygen partial at the borders equal to the oxygen partial pressure in the ambient air (i.e. $\mathrm{P}_{\mathrm{O}_{2}(\mathrm{~atm})}=$ 21278.25 Pa).

$$
\begin{aligned}
& \mathrm{A}=\frac{1-\exp \left(\sqrt{\frac{\mathrm{r}_{\mathrm{O}_{2}}}{\mathrm{D}_{\mathrm{O}_{2}}}} \mathrm{~L}\right)}{\exp \left(-\sqrt{\frac{\mathrm{r}_{\mathrm{O}_{2}}}{\mathrm{D}_{\mathrm{O}_{2}}}} \mathrm{~L}\right)-\exp \left(\sqrt{\frac{\mathrm{r}_{\mathrm{O}_{2}}}{\mathrm{D}_{\mathrm{O}_{2}}}} \mathrm{~L}\right)} \times \mathrm{P}_{\mathrm{O}_{2}(\text { atm })} \\
& \mathrm{B}=\frac{\exp \left(-\sqrt{\frac{\mathrm{r}_{\mathrm{O}_{2}}}{\mathrm{D}_{\mathrm{O}_{2}}}} \mathrm{~L}\right)-1}{\exp \left(-\sqrt{\frac{\mathrm{r}_{\mathrm{O}_{2}}}{\mathrm{D}_{\mathrm{O}_{2}}}} \mathrm{~L}\right)-\exp \left(\sqrt{\frac{\mathrm{r}_{\mathrm{O}_{2}}}{\mathrm{D}_{\mathrm{O}_{2}}}} \mathrm{~L}\right)} \times \mathrm{P}_{\mathrm{O}_{2}(\mathrm{~atm})}
\end{aligned}
$$

\section{Comparison between 1D analytical and 2D numerical solutions of the ADR}

As detailed previously, the 1D description of the ADR model is only valid comparing the $\mathrm{P}_{\mathrm{O}_{2}}$ profile along the median " $\mathrm{X}$ " axis (i.e. $L$ contact length) applied for large W/L ratios so that the ADR process generated along the transverse side can be neglected. To illustrate the $\mathrm{W} / \mathrm{L}$ ratio effect, $\mathrm{P}_{\mathrm{O}_{2}}(\mathrm{x})$ profiles are compared in Fig. 2 for two contact geometries $W / L=1$ and $W / L=4$ (fixing $L$ at $5 \mathrm{~mm}$ ). The graphs compare the complete $2 D$ model considering advection process, the $2 \mathrm{D}$ model without advection and the 1D 
approximation which neglects both the transverse ADR contribution and the advection effect. A first global overview of the log scale graphs reveals a very good prediction provided by the 1D analytical solution. However, a deeper analysis of the oxygen partial pressure for $\mathrm{W} / \mathrm{L}=1$ condition underlines a scattering regarding the minimum $\mathrm{P}_{\mathrm{O}_{2}}$ value at the contact center. Note that this difference is mainly due to the 1D hypothesis (i.e. transverse $A D R$ contribution) such that $2 \mathrm{D} \mathrm{P}_{\mathrm{O}_{2}}$ profiles with and without advection are very close. However, if we consider the prediction of the oxygen distance "do" when $\mathrm{P}_{\mathrm{O}_{2}}<\mathrm{P}_{\mathrm{O}_{2}, \text { th }}=0.1 \mathrm{~Pa}$, the error is clearly smaller. This suggests that even for the limit condition $\mathrm{L}=\mathrm{W}$, the $1 \mathrm{D}$ approximation provides a very good estimation of the partition between adhesive and abrasive wear domains at least for the studied contact. 

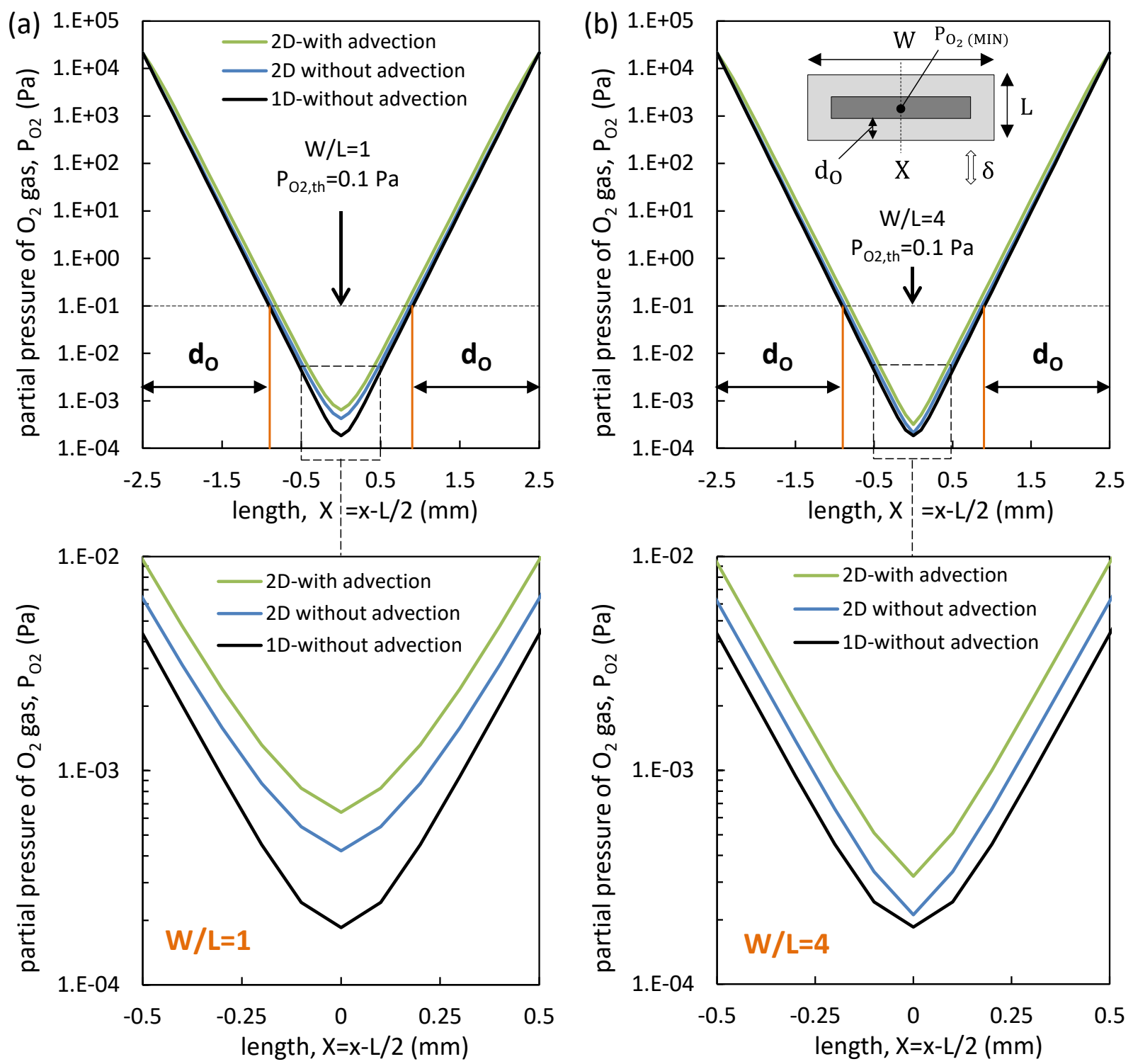

Fig.2. (a) Evolution of the $\mathrm{P}_{\mathrm{O}_{2}}$ profiles along the $X$ median axis for $W / L=1$; (b) evolution of the $\mathrm{P}_{\mathrm{O}_{2}}$ profiles along the $\mathrm{X}$ median axis for $\mathrm{W} / \mathrm{L}=4$ and $\mathrm{L}=5 \mathrm{~mm}\left(\mathrm{p}=100 \mathrm{MPa}, \delta_{\mathrm{g}}= \pm 100\right.$ $\mu \mathrm{m}$, and $\mathrm{f}=1 \mathrm{~Hz}$ corresponding to the reference condition in $[12,13])$.

This comparison of the $\mathrm{P}_{\mathrm{O}_{2}}$ profiles given for $\mathrm{W} / \mathrm{L}=4$ (with $\mathrm{L}=5 \mathrm{~mm}$ ) confirms a smaller scattering even for the central part of the contact. Indeed, increasing the W/L ratio, the ADR transverse effect along the $\mathrm{X}$ median axis is reduced and the contact evolves toward a 1D analytical approximation. However, a log scale graph tends to flatten this 
scattering. Therefore, to better quantify the comparison, two index errors comparing the minimum $\mathrm{O}_{2}$ partial pressure in the contact center and the oxygen distance "do", assuming $\mathrm{P}_{\mathrm{O}_{2}, \mathrm{th}}=0.1 \mathrm{~Pa}$, are computed.

$\Delta \mathrm{P}_{\mathrm{O}_{2}(1 \mathrm{D})}=\left|\mathrm{P}_{\mathrm{O}_{2}, 2 \mathrm{D}}(\mathrm{x}=0)-\mathrm{P}_{\mathrm{O}_{2}, 1 \mathrm{D}}(\mathrm{x}=0)\right|$

$\% d_{O(1 D)}=\left|\frac{d_{O, 2 D}\left(P_{\mathrm{O}_{2}, \text { th }}=0.1 \mathrm{~Pa}\right)-\mathrm{d}_{\mathrm{O}, 1 \mathrm{D}}\left(\mathrm{P}_{\mathrm{O}_{2}, \text { th }}=0.1 \mathrm{~Pa}\right)}{\mathrm{d}_{\mathrm{O}, 2 \mathrm{D}}\left(\mathrm{P}_{\mathrm{O}_{2}, \text { th }}=0.1 \mathrm{~Pa}\right)}\right| \times 100$

To evaluate the relative influence of the advection contribution two additional index errors are estimated using the $2 \mathrm{D}$ numerical simulations with and without advection process.

$\Delta \mathrm{P}_{\mathrm{O}_{2}(\mathrm{adv})}=\left|\mathrm{P}_{\mathrm{O}_{2}, 2 \mathrm{D}}(\mathrm{x}=0)-\mathrm{P}_{\mathrm{O}_{2}, 2 \mathrm{D}}(\mathrm{x}=0, \mathrm{adv}=0)\right|$

$\% \mathrm{~d}_{\mathrm{O}(\mathrm{adv})}=\left|\frac{\mathrm{d}_{\mathrm{O}, 2 \mathrm{D}}\left(\mathrm{P}_{\mathrm{O}_{2}, \text { th }}=0.1 \mathrm{~Pa}\right)-\mathrm{d}_{\mathrm{O}, 2 \mathrm{D}}\left(\mathrm{P}_{\mathrm{O}_{2}, \mathrm{th}}=0.1 \mathrm{~Pa}, \mathrm{adv}=0\right)}{\mathrm{d}_{\mathrm{O}, 2 \mathrm{D}}\left(\mathrm{P}_{\mathrm{O}_{2}, \text { th }}=0.1 \mathrm{~Pa}\right)}\right| \times 100$

Hence, $\Delta \mathrm{P}_{\mathrm{O}_{2}(1 \mathrm{D})}$ and $\% \mathrm{~d}_{\mathrm{O}(1 \mathrm{D})}$ index errors measure the maximum error between the complete ADR model versus the $1 \mathrm{D}$ analytical expression. However, $\Delta \mathrm{P}_{\mathrm{O}_{2} \text { (adv) }}$ and $\% \mathrm{~d}_{\mathrm{O} \text { (adv) }}$ measure the relative errors induced when neglecting the advection process in the 2D numerical solutions. Finally, the error differences between these two errors $\left(\Delta \mathrm{P}_{\mathrm{O}_{2}(1 \mathrm{D})}-\Delta \mathrm{P}_{\mathrm{O}_{2}(\text { adv })}\right)$ and $\left(\% \mathrm{~d}_{\mathrm{O}(1 \mathrm{D})}-\% \mathrm{~d}_{\mathrm{O}(\mathrm{adv})}\right)$ illustrate the effect of transverse contributions on the minimum $\mathrm{P}_{\mathrm{O}_{2}}$ and $\% \mathrm{~d}_{\mathrm{O}}$ values respectively. This index error analysis is generalized to plot the evolution of $\Delta \mathrm{P}_{\mathrm{O}_{2}(1 \mathrm{D})}$ and $\Delta \mathrm{P}_{\mathrm{O}_{2} \text { (adv) }}$ then $\% \mathrm{~d}_{\mathrm{O}(1 \mathrm{D})}$ and $\% \mathrm{~d}_{\mathrm{O}(\text { (adv) }}$ versus W/L in Fig. 3a and Fig. 3b respectively.

Asymptotic decreasing evolutions are observed confirming that when $\mathrm{W} / \mathrm{L}$ exceeds 1 , the given 1D analytical formulation provides rather good estimation of the minimum oxygen partial pressure and above all a good prediction of the oxygen distance. Note 
that in addition to the $P_{O_{2}}$ variable, the oxygen distance $d_{O}$ was established by previous study [11] as a key parameter to quantify the partition of adhesive and abrasive wear domains in the fretting interface. The very good prediction of the $d_{O}$ values for $\mathrm{W} / \mathrm{L}>1$ suggests that despite its simplicity, the 1D analytical formulation appears as a very useful strategy to quantify the contact oxygenation process under gross slip fretting interface.

Besides, the comparison between $\Delta \mathrm{P}_{\mathrm{O}_{2}(1 \mathrm{D})}$ and $\Delta \mathrm{P}_{\mathrm{O}_{2}(\text { adv })}$ and then $\% \mathrm{~d}_{\mathrm{O}(1 \mathrm{D})}$ and $\% \mathrm{~d}_{\mathrm{O} \text { (adv) }}$ respectively suggests that most of the error is in fact induced by the transverse ADR contribution rather than by the advection effect whose contribution appears negligible compared with the diffusion process. 

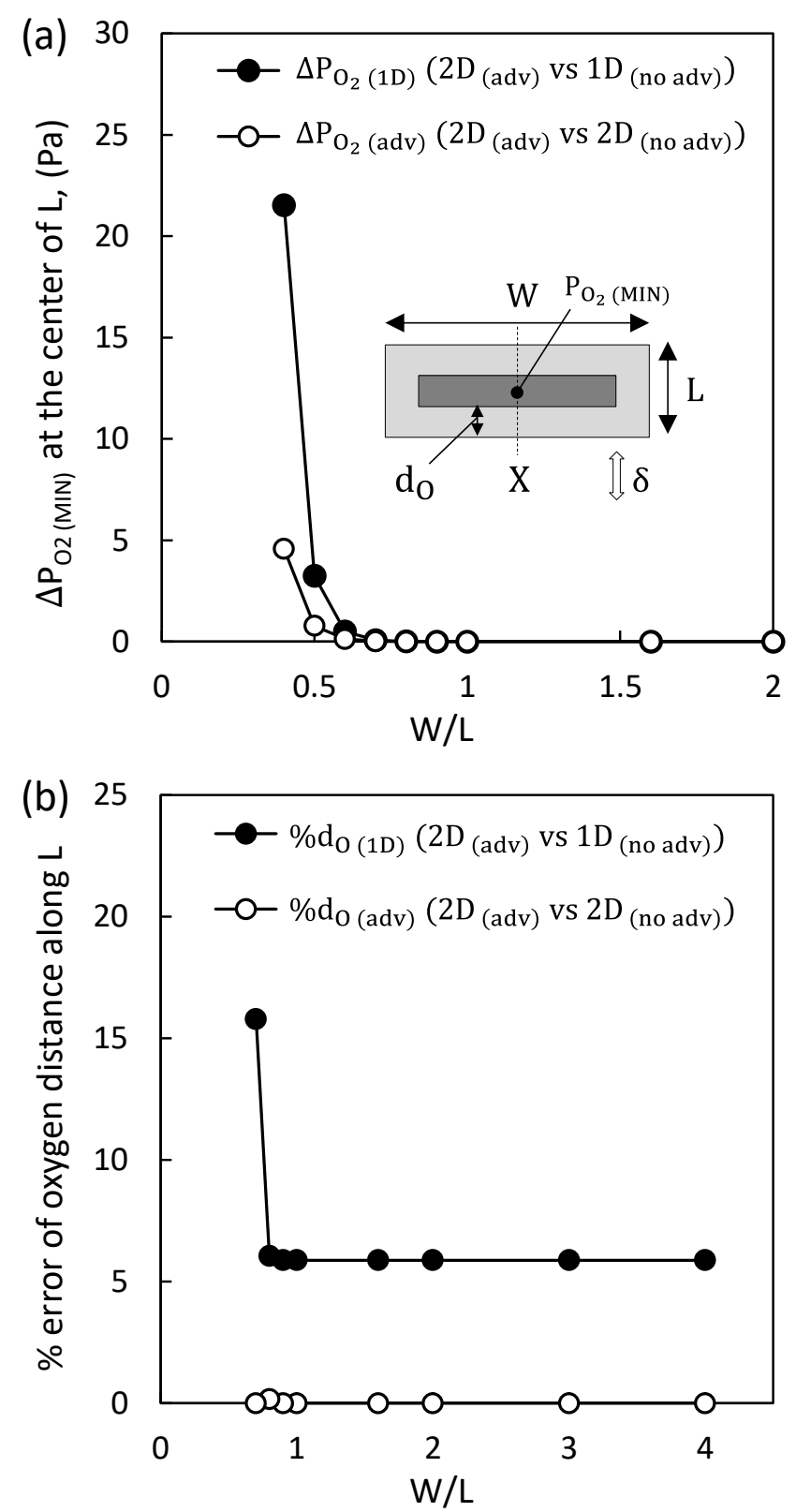

Fig.3. (a) Evolution of $\Delta \mathrm{P}_{\mathrm{O}_{2} \text { (1D) }}$ and $\Delta \mathrm{P}_{\mathrm{O}_{2} \text { (adv) }}$ index errors versus W/L ratio; (b) evolution of $\% \mathrm{~d}_{\mathrm{O}(1 \mathrm{D})}$ and $\% \mathrm{~d}_{\mathrm{O}(\mathrm{adv})}$ index errors versus $\mathrm{W} / \mathrm{L}$ ratio estimated for a nonzero adhesion zone $\left(p=100 \mathrm{MPa}, \delta_{g}= \pm 100 \mu \mathrm{m}\right.$, and $\left.\mathrm{f}=1 \mathrm{~Hz}\right)$.

\section{Experimental validation of the analytical solution of the ADR model}

The 1D analytical approximation of the ADR model previously validated after being compared with a complete 2D numerical simulation is now confronted with experiments. 
The studied contact geometry consists in a rectangular 34NiCrMo16 flat-on-flat configuration such that the transverse width $(\mathrm{W}=10 \mathrm{~mm})$ is chosen at least three times longer than the collinear contact length $(L=3 \mathrm{~mm})$ leading to a $W / L$ ratio $=3.33$ with an apparent contact area $A=30 \mathrm{~mm}^{2}$. This contact configuration permits assuming a onedimensional evolution of the interfacial oxygen flow along the collinear contact length "L" by considering that the transverse width "W" is sufficiently large with respect to "L". A hydraulic test machine, specific for testing large flat contacts (see Ref. $[12,18]$ ) is used to perform the experiments.

Following this, a cross-experimental campaign is considered to evaluate the capacity of the analytical solution of the ADR to predict the oxygen distance "do" and the partition between adhesive and abrasive wear domains. All the tests are performed at ambient temperature $\left(25^{\circ} \mathrm{C} \pm 5^{\circ} \mathrm{C}\right)$ and relative humidity $(\mathrm{RH}=40 \% \pm 10 \%)$. Starting from a reference test having number of fretting cycles $\mathrm{N}=20000$ cycles, sliding amplitude $\delta_{g}= \pm 100 \mu \mathrm{m}$, contact pressure $p=100 \mathrm{MPa}$, sliding frequency $\mathrm{f}=1 \mathrm{~Hz}$, contact transverse width $\mathrm{W}=10 \mathrm{~mm}$ and collinear length $\mathrm{L}=3 \mathrm{~mm}\left(A=30 \mathrm{~mm}^{2}\right)$, two parameters are tested. First, the sliding frequency is varied from 1 to $15 \mathrm{~Hz}$ while maintaining the other parameters the same as the reference condition. Following this, the contact pressure is varied from 25 to $150 \mathrm{MPa}$ while fixing the other parameters (Fig. 4b). Then, oxygen partial pressure is estimated by applying Eq. 15 along the collinear length $L=3 \mathrm{~mm}$ from which the numerical oxygen distance can computed (Fig. 3). This permits estimating adhesive wear area which is compared to the experimental results obtained using EDX maps as detailed in [12] assuming isotropic oxygen distance. 

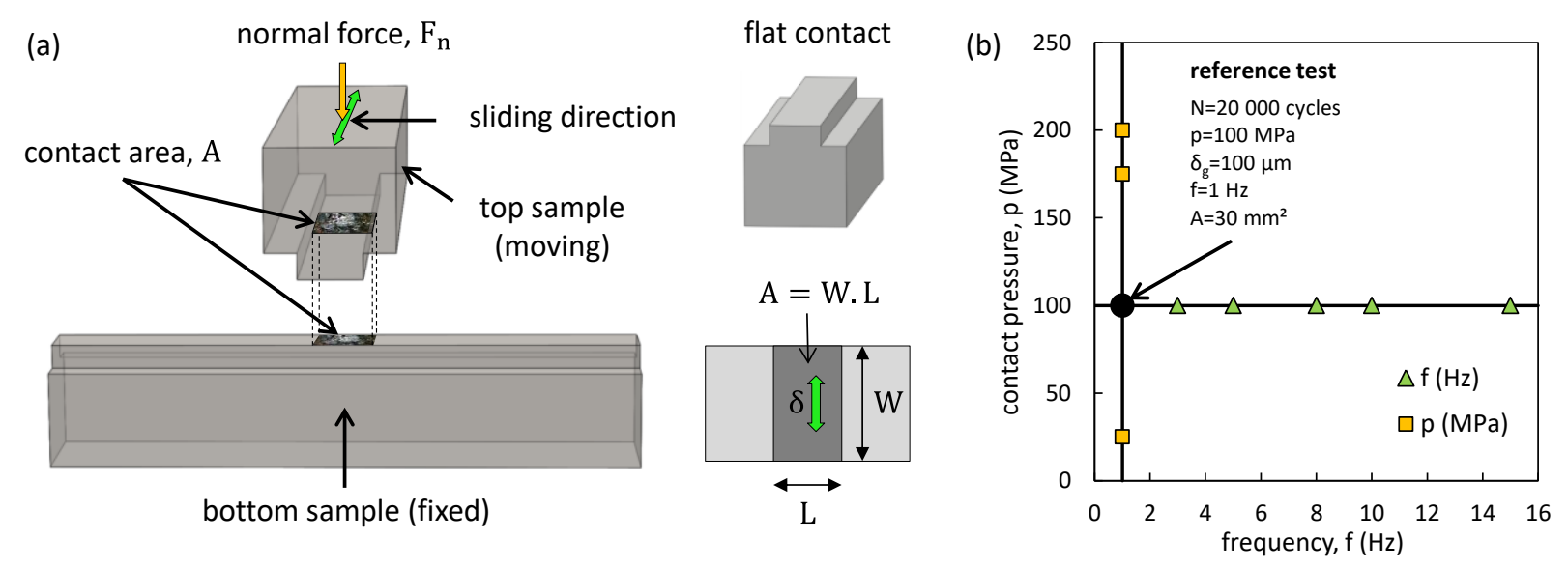

Fig. 4. (a) Schematic illustration of the rectangular crossed flat-on-flat configuration; (b) cross-experimental campaign used to validate the analytical solution of the ADR.

\section{Results}

Fig. 5 compares the experimental and the predicted evolution of the fretting scar and the adhesive wear extension by the ADR analytical solution as a function of the Archard power density factor while varying the contact pressure and the sliding frequency. It appears that by increasing the friction power dissipated at the interface, the contact shifts from pure abrasive to mixed abrasive-adhesive wear with a noticeable growth of the internal adhesion zone with the increase of $\omega^{*}$. As suggested by the contact oxygenation concept $(\mathrm{COC})$, this is due to the higher consumption of oxygen at the borders induced by the oxidation of the freshly exposed metal surface by friction process. Hence, there will be oxygen gas depletion towards the center favoring adhesive wear (Fig. 1 \& 2). Such tendency is elegantly captured by the analytical solution of the ADR model which mimics the expansion of the internal rectangular adhesion zone at a wide range of loading conditions. 


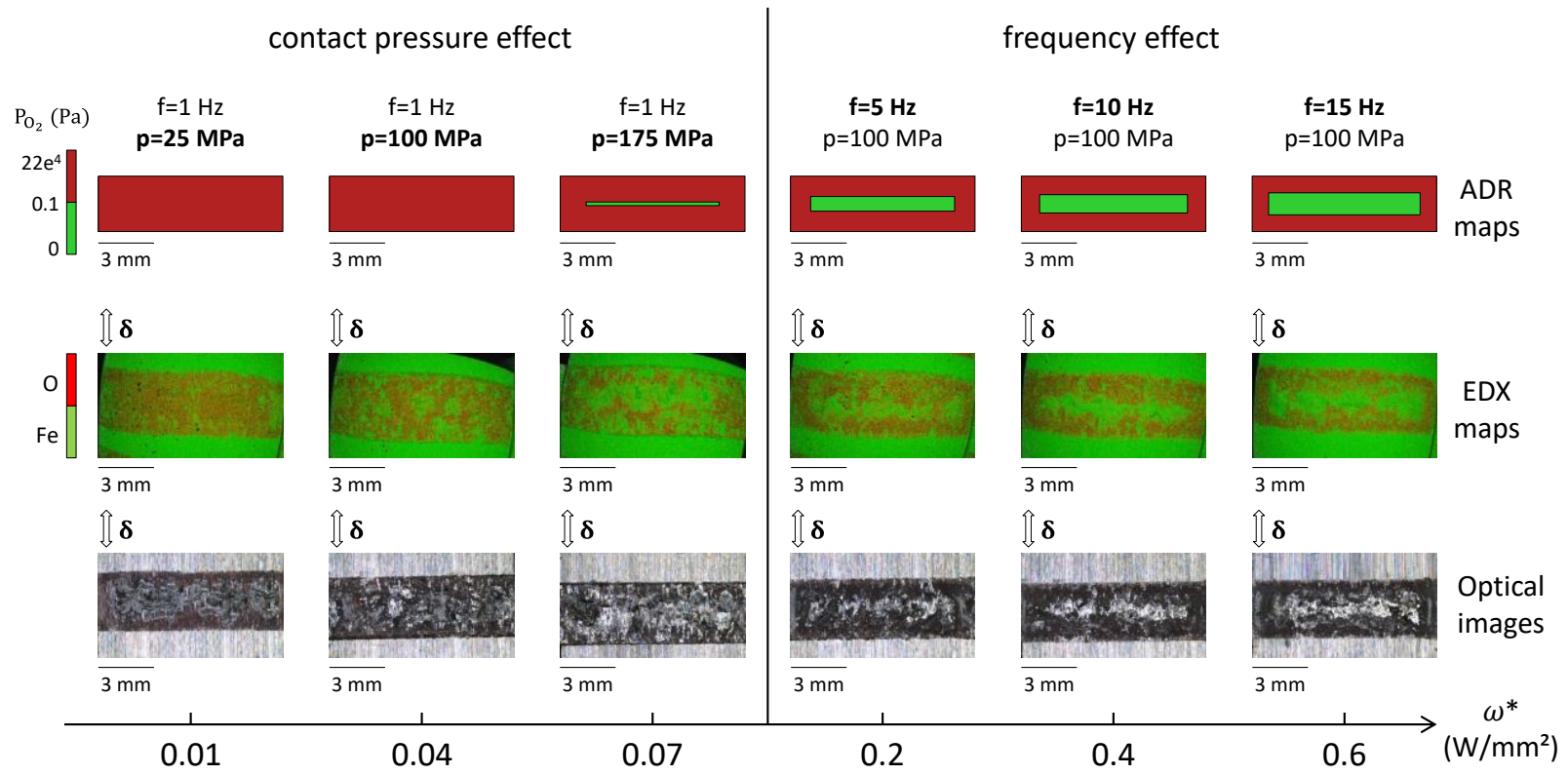

Fig. 5. Comparison between the optical images, EDX maps and the analytical ADR maps for the top samples displaying the growth of the adhesion zone with the increase in the Archard power density factor $\omega^{*}=\mathrm{p} \times \mathrm{v}=4$. p. $\delta_{\mathrm{g}}$. f from 0.01 to $0.6 \mathrm{~W} / \mathrm{mm}^{2}$ $\left(\mathrm{N}=20000\right.$ cycles, $\delta_{g}= \pm 100 \mu \mathrm{m}$, and $\left.A=3 \times 10=30 \mathrm{~mm}^{2}\right)$.

The above evolution is quantified in Fig. 6 where the experimental oxygen distance values $\left(\mathrm{d}_{0, \exp }\right)$ are compared with those predicted by the 1D ADR simplified analytical solution $\left(\mathrm{d}_{\mathrm{O}, 1 \mathrm{D}}\right)$ extracted from Eq. 15. Note that the evolution of $\mathrm{d}_{\mathrm{O}, 1 \mathrm{D}}$, which corresponds to the distance from the contact borders to the position where $\mathrm{P}_{\mathrm{O}_{2}}(\mathrm{x})=$ $\mathrm{P}_{\mathrm{O}_{2}, \text { th }}=0.1 \mathrm{~Pa}$, can be approximated by a simple power law function such that $\mathrm{d}_{0,1 \mathrm{D}}=$ $0.89 \times \omega^{*-0.14}$. As expected, both experiments and simulations display an asymptotic decrease versus the Archard power density factor (i.e. " $\omega^{*}=$ p.v" factor). Combining the effects of the contact pressure and the siding frequency, it appears clearly that the given " $\mathrm{d}_{\mathrm{O}, 1 \mathrm{D}}$ " formulation provides a very good estimation of the experiments " $\mathrm{d}_{0, \exp }$ ". However, the analytical solution appears to better predict the effect of the sliding 
frequency than the contact pressure. The overestimation of the contact pressure effect could be attributed to the fact that the given ADR model assumes a constant debris bed porosity which is not the case when varying the contact pressure as the latter compacts the debris bed leading to lower porosity values.

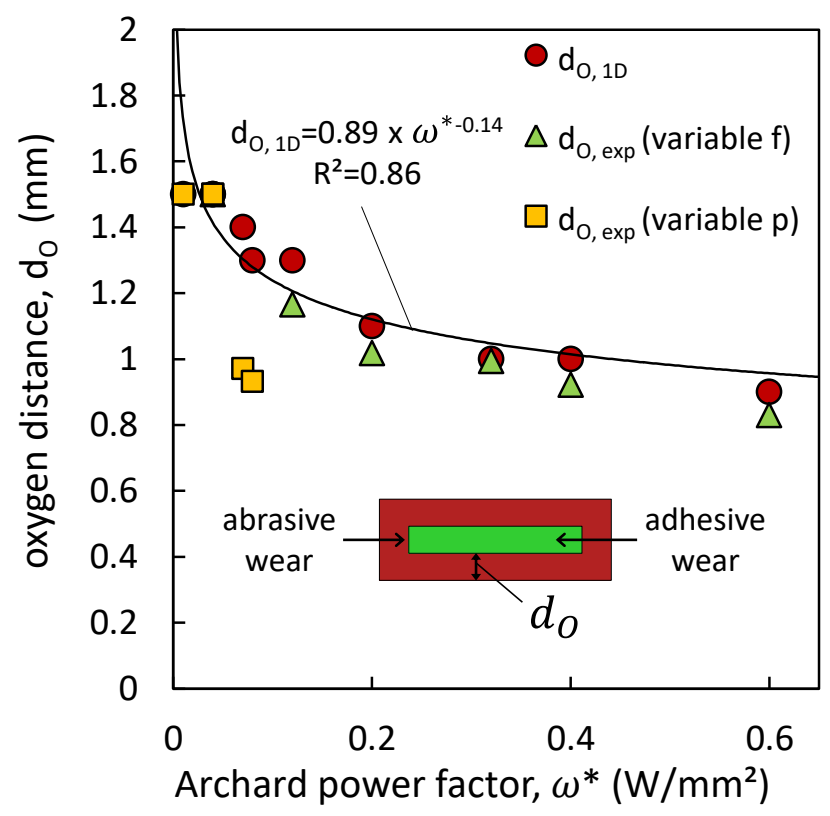

Fig. 6. Correlation between the experimental $\left(\mathrm{d}_{\mathrm{O}, \text { exp }}\right)$ and the predicted oxygen distance from ADR approach $\left(\mathrm{d}_{0,1 \mathrm{D}}\right)$ as a function of the Archard power density factor $\omega^{*}=p \times$ $\mathrm{v}=4$. $\mathrm{p} \cdot \delta_{\mathrm{g}} \cdot \mathrm{f}\left(\mathrm{N}=20000\right.$ cycles, $\delta_{\mathrm{g}}= \pm 100 \mu \mathrm{m}$, and $\left.\mathrm{A}=3 \times 10=30 \mathrm{~mm}^{2}\right)$.

The ADR model predictions through the one dimensional analytical solution proposed in Eq. 15 for rectangular and square contacts are combined with the predictions of the ADR axisymmetric analytical solution for circular flat contacts (formerly proposed in [13]) in Fig. $7 a, b$ \&c. The results of 50 tests considering variable contact pressure, sliding frequency, and contact size for flat circular, rectangular (linear) and square contacts are compiled. Such combination uncovers a strong correlation between the experimental 
and the given ADR analytical oxygen distance prediction which definitively confirms the interest of such simple closed form expressions. This indirectly lends support to the fact that advection contribution can be neglected at least for the studied conditions. It also suggests that using these simple expressions a direct link can be established between contact loadings and the adhesive/abrasive wear distributions within fretting interface. This development is expected to allow basic multiphysics analysis of the fretting wear contacts. 

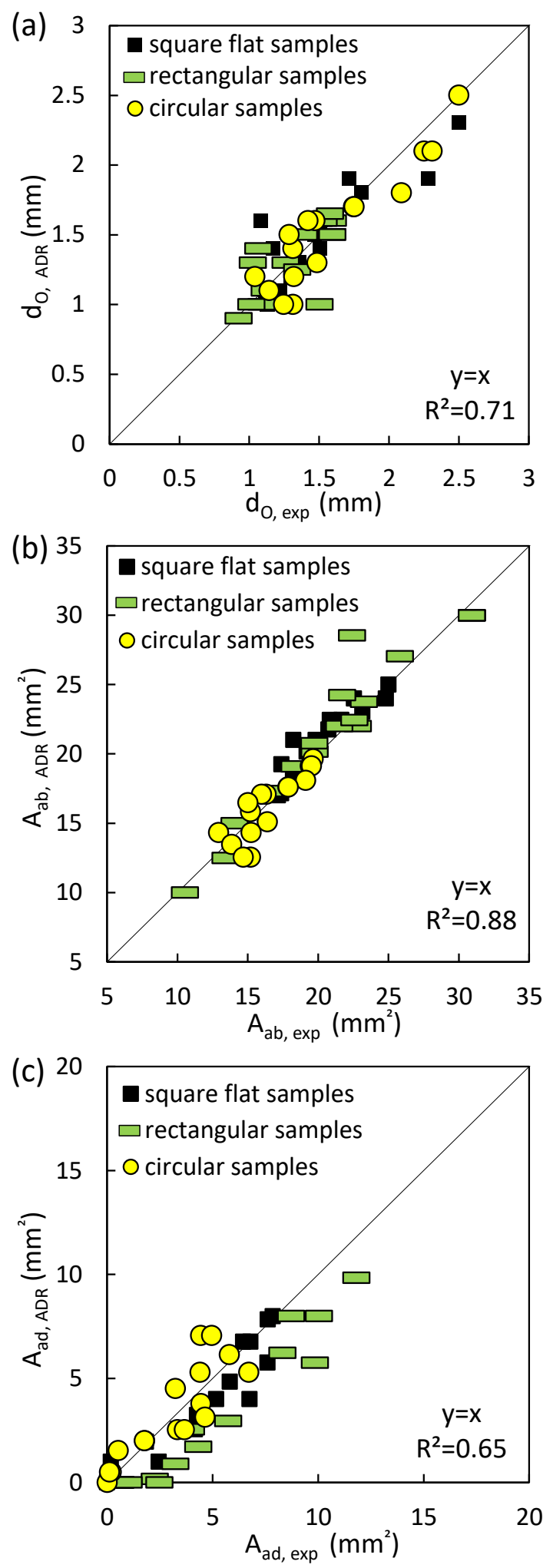

Fig. 7. Comparison between the experimental and the analytical ADR prediction given by 1D (Eq. 15) and axisymmetric (Eq. 4) formulations (i.e. Eq. 15 for rectangular and 
square contacts and Eq. 4 for axisymmetric circular contact) for (a) the oxygen distance " $\mathrm{d}_{\mathrm{O}}$ "; (b) the abrasion area " $\mathrm{A}_{\mathrm{ab}}$ "; and (c) the adhesion area " $\mathrm{A}_{\mathrm{ad}}$ ".

\section{Discussion}

Explicit closed-form expressions of the ADR modelling are derived for axisymmetric and 1D contact configuration. Using this approach, the oxygen distance $d_{0}$ (i.e. the extension of the abrasive wear domain) as well as the partition between the inner adhesive wear domain and the surrounding abrasion zone can be estimated. A very good correlation with the experimental results suggest that despite the simplifications made, the given explicit formulations of the $\mathrm{COC}$ modeling appear reliable and above all efficient to predict the extension of the adhesive wear domain in fretting interfaces. The model considers a steady state hypothesis which is indirectly supported by a stable evolution of the friction coefficient and a linear increase of the wear volume above 5000 cycles [18].

However, the long term stability of the partition between adhesive and abrasive wear domain (i.e. $d_{0}$ length) is still an open question. A dynamic description of the fretting scar morphology should be considered to better interpret COC process. Indeed, at the beginning of the fretting test, the native oxide layer is progressively removed inducing direct metal-metal interactions and formation of the first metal debris. Note that this process is activated even for very low mean contact pressures since incipient damage processes are activated at the asperity scale where plasticity occurs as depicted by Greenwood's theory.

Then, as suggested by COC, the morphology of the wear debris and the related wear mechanisms will depend on the local contact oxygenation condition: 
- If these worn debris particles are located in a domain where the contact oxygenation is effective (i.e. $\mathrm{P}_{\mathrm{O}_{2}}(\mathrm{x}, \mathrm{y})>\mathrm{P}_{\mathrm{O}_{2} \text {,th }}$ ), this metallic wear debris will oxidize leading to oxidoabrasive wear process.

- If these incipient metallic wear debris are located in a contact domain where the contact oxygenation is deprived (i.e. $\mathrm{P}_{\mathrm{O}_{2}}(\mathrm{x}, \mathrm{y})<\mathrm{P}_{\mathrm{O}_{2}, \text { th }}$ ), these metallic wear debris will agglomerate leading to an adhesive metallic third body structure.

The partition between these two third-body structures (i.e. $d_{0}$ ) depends on the contact loading conditions but can also evolve with the test duration and the structure of the third-body layer. Zhu et al. $[10,19,20]$, investigating very long cylinder-on-flat contact fretting tests, suggested that above $10^{6}$ fretting cycles the inner adhesive wear domain observed at the beginning of the test disappears. To interpret this result, it must be underlined that for a non-conformal contact like cylinder-on-flat, the surface wear promotes an extension of the contact area which tends to expand the inner adhesive wear domain. However, in the meantime, the mean contact pressure decreases which favors the contact oxygenation process. Therefore, the evolution of $d_{0}$ (i.e. the partition of adhesive and abrasive wear domains) can be related to the balance between these two opposite effects which can explain that for very long tests, where $\mathrm{P}_{\mathrm{O}_{2}}$ becomes lower than $\mathrm{P}_{\mathrm{O}_{2} \text {,th }}$ over the whole fretted interface, the interface shifts toward a pure abrasive wear scar. In the present flat-on-flat contact investigation, contact area and mean contact pressure remain nearly constant and therefore the composite adhesive-abrasive fretting scar morphology is more stable. 
The dynamic evolution of $d_{O}$ parameter not only depends on the global contact loadings but also on the local wear process as depicted by Arnaud et al. [21]. Indeed, in this multiphysics research work, both the surface wear and COC processes were coupled to simulate the wear profiles and adhesive/abrasive wear partition of TA6V cylinder-on-flat contact. This work suggests that steady state wear extension implies a homogeneous increment of the wear depth over the whole wear regime is achieved. Therefore, to compensate the lower rate of the inner adhesive wear domain, higher friction energy density and consequently higher contact pressures should operate in the adhesive wear domain compared to the lateral abrasive zones. This generates peak pressure at the $d_{0}$ boundary between adhesive and abrasive wear domains (Fig. 16 in [21]). These local peak pressures reduce the oxygen diffusion and in turn stabilize the presence of an inner adhesive domain in the fretting interface as suggested by Fig. 17 in [21].

Hence, the adhesive wear domain remains constant in size although the lateral abrasive wear domains extend with the surface wear extension. To conclude, the long term evolution of the partition between the adhesive and the abrasive wear domain is a complex process, involving a local description of $\mathrm{COC}$ but also a local surface wear analysis. Future research works coupling local multiphysics simulations and very long fretting wear experiments will be undertaken to clarify this subject.

\section{Conclusion}

This paper provides analytical solutions of the Advection-Dispersion-Reaction (ADR) modelling of the contact oxygenation concept. The analytical solution of the ADR is 
obtained by assuming one dimensional contact configuration. Results show that despite the simplifications made, the analytical solutions provide a very good approximation of the predictions given by the complete $2 \mathrm{D}$ numerical simulations. If the ratio between the transverse and the longitudinal lengths is larger than 1 (i.e. $W / L \geq 1$ ), these basic formulations not only capture the extension of adhesive wear but also the transition from pure abrasive to a composite abrasive-adhesive wear for a broad range of fretting loadings and flat contact geometries.

\section{Acknowledgements}

The authors gratefully acknowledge the French National Research Agency (ANR, France) and the Ecole Centrale de Lyon (ECL, France) for financially supporting this research project (ANR-16-CE08-0016).

\section{References}

[1] P.L. Hurricks, The mechanism of fretting-A review, Wear. 15 (1970) 389-409. doi:10.1016/0043-1648(70)90235-8.

[2] O. Vingsbo, S. Soderberg, On fretting maps, Wear. 126 (1988) 131-147. doi:10.1016/0043-1648(88)90134-2.

[3] D. Tabor, Wear-A Critical Synoptic View, J. Lubr. Technol. 99 (2010) 387. doi:10.1115/1.3453231.

[4] J. Juoksukangas, V. Nurmi, J. Hintikka, M. Vippola, A. Lehtovaara, A. Mäntylä, J. Vaara, T. Frondelius, Characterization of cracks formed in large flat-on-flat fretting contact, Int. J. Fatigue. 124 (2019) 361-370. doi:10.1016/j.ijfatigue.2019.03.004.

[5] C. Mary, S. Fouvry, J.M. Martin, B. Bonnet, Pressure and temperature effects on Fretting Wear damage of a Cu-Ni-In plasma coating versus Ti17 titanium alloy contact, Wear. 272 (2011) 18-37. doi:10.1016/j.wear.2011.06.008.

[6] S. Fouvry, P. Arnaud, A. Mignot, P. Neubauer, Contact size, frequency and cyclic normal force effects on Ti-6Al-4V fretting wear processes: An approach combining friction power and contact oxygenation, Tribol. Int. 113 (2017) 460-473. doi:10.1016/j.triboint.2016.12.049.

[7] A.R. Warmuth, S.R. Pearson, P.H. Shipway, W. Sun, The effect of contact geometry on fretting wear rates and mechanisms for a high strengthsteel, Wear. 301 (2013) 491-500. doi:10.1016/j.wear.2013.01.018.

[8] A.R. Warmuth, P.H. Shipway, W. Sun, Fretting wear mapping: The influence of contact geometry and frequency on debris formation and ejection for a steel-on-steel pair, Proc. R. Soc. A Math. Phys. Eng. Sci. 471 (2015). doi:10.1098/rspa.2014.0291.

[9] A.M. Kirk, W. Sun, C.J. Bennett, P.H. Shipway, Interaction of displacement amplitude and frequency effects in fretting wear of a high strength steel: Impact on debris bed formation and subsurface damage, Wear. $482-483$ (2021) 203981. doi:10.1016/j.wear.2021.203981.

[10] P.H. Shipway, A.M. Kirk, C.J. Bennett, T. Zhu, Understanding and modelling wear rates and mechanisms in fretting via the concept of rate-determining processes - Contact oxygenation, debris formation and debris ejection, Wear. 486-487 (2021) 204066. doi:10.1016/j.wear.2021.204066.

[11] S. Baydoun, S. Fouvry, An experimental investigation of adhesive wear extension in fretting interface: Application of the contact oxygenation concept, Tribol. Int. 147 (2020) 106266. doi:10.1016/j.triboint.2020.106266.

[12] S. Baydoun, P. Arnaud, S. Fouvry, Modelling adhesive wear extension in fretting interfaces: An advection-dispersionreaction contact oxygenation approach, Tribol. Int. 151 (2020) 106490. doi:10.1016/j.triboint.2020.106490.

[13] S. Baydoun, P. Arnaud, S. Fouvry, Modeling contact oxygenation and adhesive wear extension in axisymmetric flat circular 
fretting interfaces, Wear. 477 (2021) 203822. doi:10.1016/j.wear.2021.203822.

[14] C. Mary, T. Le Mogne, B. Beaugiraud, B. Vacher, J.M. Martin, S. Fouvry, Tribochemistry of a Ti alloy under fretting in air: Evidence of titanium nitride formation, Tribol. Lett. 34 (2009) 211-222. doi:10.1007/s11249-009-9426-6.

[15] I. Argatov, G. Mishuris, Contact Mechanics of Articular Cartilage Layers, 2015.

[16] M. Huysmans, A. Dassargues, Review of the use of Péclet numbers to determine the relative importance of advection and diffusion in low permeability environments, Hydrogeol. J. 13 (2005) 895-904. doi:10.1007/s10040-004-0387-4.

[17] T. Moldrup, $\mathrm{P}$ and Kruse, CW and Rolston, DE and Yamaguchi, Modeling diffusion and reaction in soils: III. Predicting gas diffusivity from the Campbell soil-water retention model, Soil Sci. 161 (1996) 366-375. doi:10.1097/00010694-19960600000003.

[18] S. Baydoun, S. Fouvry, S. Descartes, P. Arnaud, Fretting wear rate evolution of a flat-on-flat low alloyed steel contact: A weighted friction energy formulation, Wear. 426-427 (2019) 676-693. doi:10.1016/j.wear.2018.12.022.

[19] T. Zhu, P.H. Shipway, W. Sun, The dependence of wear rate on wear scar size in fretting; the role of debris (third body) expulsion from the contact, Wear. 440-441 (2019) 203081. doi:10.1016/j.wear.2019.203081.

[20] T. Zhu, P.H. Shipway, Contact size and debris ejection in fretting: The inappropriate use of Archard-type analysis of wear data and the development of alternative wear equations for commonly employed non-conforming specimen pair geometries, Wear. 474-475 (2021) 203710. doi:10.1016/j.wear.2021.203710.

[21] P. Arnaud, S. Baydoun, S. Fouvry, Modeling adhesive and abrasive wear phenomena in fretting interfaces: A multiphysics approach coupling friction energy, third body and contact oxygenation concepts, Tribol. Int. 161 (2021) 107077. doi:10.1016/j.triboint.2021.107077. 